Пячин С. А., Бурков А. А., Власова Н. М., Кириченко Е. А., Мокрицкий Б. Я., Зайкова Е. Р. S. A. Pyachin, A. A. Burkov, N. M. Vlasova, Ye. A. Kirichenko, B. Ys. Mokritskii, E. R. Zaikova

ИЗНОСОСТОЙКОСТЬ И ЖАРОСТОЙКОСТЬ ЭЛЕКТРОИСКРОВЫХ ПОКРЫТИЙ НА ОСНОВЕ Ті 3 АІ С ДОБАВКОЙ КАРБИДА БОРА

\title{
WEAR RESISTANCE AND HEAT RESISTANCE OF THE ELECTRIC SPARK COATINGS BASED ON TI3AI WITH THE ADDITION OF BORON CARBIDE
}

Пячин Сергей Анатольевич - кандидат физико-математических наук, доцент, заведующий лабораторией функциональных материалов и покрытий Федерального государственного бюджетного учреждения науки, Института материаловедения Хабаровского научного центра ДВО РАН (Россия, г. Хабаровск); 680042, г. Хабаровск, ул. Тихоокеанская, 153, тел. (4212)22-56-98. E-mail: pyachin@mail.ru.

Mr. Sergei A. Pyachin - PhD in Physical and Mathematical Sciences, associate Professor, head of functional materials and coatings laboratory, Institute of Materials, Far Eastern Branch, the Russian Academy of Sciences (Russia, Khabarovsk); 680042, Khabarovsk, Tikhookeanskaya st., 153, tel.: (4212)22-56-98. E-mail: pyachin@mail.ru.

Бурков Александр Анатольевич - кандидат физико-математических наук, научный сотрудник Федерального государственного бюджетного учреждения науки, Института материаловедения Хабаровского научного центра ДВО РАН (Россия, г. Хабаровск); 680042, г. Хабаровск, ул. Тихоокеанская, 153, тел. (4212)22-5698. E-mail: burkovalex@mail.ru.

Mr. Alexander A. Burkov - PhD in Physical and Mathematical Sciences, researcher, Institute of Materials, Far Eastern Branch, the Russian Academy of Sciences (Russia, Khabarovsk); 680042, Khabarovsk, Tikhookeanskaya st., 153, tel.: (4212)22-56-98. E-mail: burkovalex@mail.ru.

Власова Нурия Мунавировна - кандидат технических наук, научный сотрудник Федерального государственного бюджетного учреждения науки, Института материаловедения Хабаровского научного центра ДВО РАН (Россия, г. Хабаровск); 680042, г. Хабаровск, ул. Тихоокеанская, 153, тел. (4212)22-56-98. E-mail: vlasova64@yandex.ru.

Ms. Nuriya M. Vlasova - PhD in Engineering, researcher, Institute of Materials, Far Eastern Branch, the Russian Academy of Sciences (Russia, Khabarovsk); 680042, Khabarovsk, Tikhookeanskaya st., 153, tel.: (4212)22-56-98. E-mail: vlasova64@yandex.ru.

Кириченко Евгений Александрович - старший инженер, Федеральное государственное бюджетное учреждение науки Институт материаловедения Хабаровского научного центра ДВО РАН (Россия, г. Хабаровск); 680042, г. Хабаровск, ул. Тихоокеанская, 153, тел. (4212)22-56-98. E-mail: himicc@mail.ru.

Mr. Yevgeny A. Kirichenko - senior engineer, Institute of Materials, Far Eastern Branch, the Russian Academy of Sciences (Russia, Khabarovsk); 680042, Khabarovsk, Tikhookeanskaya st., 153, tel.: (4212)22-56-98. E-mail: himicc@mail.ru.

Мокрицкий Борис Яковлевич - доктор технических наук, профессор кафедры «Технология машиностроения» Федерального государственного бюджетного образовательного учреждения высшего образования «Комсомольский-на-Амуре государственный технический университет» (Россия, г. Комсомольск-наамуре); 681013, Хабаровский край, г. Комсомольск-на-Амуре, пр. Ленина, 27. E-mail^boris@knastu.ru.

Mr. Boris Ya. Mokritskii - Doctor of Engineering, professor, Mechanical Engineering Department, Komsomolsk-on-Amur State Technical University (Russia, Komsomolsk-on-Amur); 681013, Komsomolsk-on-Amur, Lenin Ave., 27. E-mail: boris@knastu.ru.

Зайкова Екатерина Романовна - магистр кафедры физика Федерального государственного бюджетного образовательного учреждения высшего профессионального образования «Тихоокеанский государственный университет» (Россия, г. Хабаровск), 680035, г. Хабаровск, ул. Тихоокеанская, 136, тел. (4212)22-43-47. E-mail: i2011023403@gmail.com.

Ms. Ekaterina R. Zaikova - Master's Degree student, Department of Physics, Pacific National University (Russia, Khabarovsk); 680042, Khabarovsk, Tikhookeanskaya st., 136, tel. (4212) 22-43-47. E-mail: i2011023403@gmail.com. 
Аннотация. Методом порошковой металлургии созданы электродные материалы из алюминида титана $\mathrm{Ti}_{3} \mathrm{Al}$ с добавкой карбида бора, которые были использованы для нанесения защитных электроискровых покрытий на титановый сплав ВТ20. Проведены испытания полученных интерметаллидных покрытий на истирание при трении с микроабразивным порошком, а также на жаростойкость при изотермическом нагреве в среде воздуха при $900{ }^{\circ} \mathrm{C}$. Показано, что за счет нанесения покрытия на сплав ВТ20 удается повысить его износостойкость в 2,5 раза. Скорость высокотемпературного окисления титанового сплава с покрытием в 4 раза меньше, чем у непокрытого материала.

Summary. The titanium aluminide $\mathrm{Ti}_{3} \mathrm{Al}$ electrode materials with a boron carbide addition were prepared by powder metallurgy and have been used for the electric spark deposition of protective coatings on titanium alloy VT20. The tests of the obtained intermetallic coatings for abrasion by friction with micro abrasive powder as well as oxidation resistance under isothermal heating in air at $900{ }^{\circ} \mathrm{C}$ were carried on. It is shown that by covering the alloy VT20 it is possible to increase its wear resistance by 2.5 times. The oxidation rate of coated titanium alloy was 4 times less than that of uncoated material.

Ключевые слова: электроискровое легирование, титановый сплав, алюминид титана, карбид бора, микроабразивный износ, жаростойкость, микротвердость.

Key words: electric spark deposition, titanium, titanium aluminide, boron carbide, micro abrasive wear, oxidation resistance, micro hardness.

УДК $621.762 ; 537.523 .4$

\section{Введение}

При использовании титановых сплавов в промышленности возникают проблемы, связанные с их высокой вязкостью при трении, сравнительно низкой жаростойкостью и высокотемпературным охрупчиванием $[1 ; 2]$. Традиционными способами устранения этих недостатков являются модифицирование состава и структуры титановых сплавов посредством выбора оптимальных условий литья и применения легирующих добавок [3; 4; 5], а также нанесение защитных покрытий [6]. Интерметаллиды как материал для нанесения защитных покрытий на титановые сплавы имеют ряд преимуществ, поскольку обеспечивают высокую адгезию с подложкой и повышают ее коррозионную стойкость. Среди подобного класса материалов особо следует выделить интерметаллиды бинарной системы Ti-Al, обладающие низкой плотностью, высокой прочностью, стойкостью к воздействию высоких температур и агрессивных сред [7]. Для нанесения Ti-Al покрытий используют различные физико-химических методы: вакуумно-дуговое испарение, ионную имплантацию, лазерную наплавку и др. $[8 ; 9 ; 10 ; 11 ; 12]$. Одним из перспективных методов для создания интерметаллидных покрытий является технология электроискрового легирования (ЭИЛ), которая основана на переносе металлов с анода на катод при циклическом воздействии электрических разрядов [13]. Электроискровые покрытия характеризуются однородностью состава поверхностного слоя за счет перемешивания металлов электродов в расплавленном состоянии и высокой адгезией с материалом подложки. Эффективность метода ЭИЛ для создания интерметаллидных покрытий подтверждается результатами наших предыдущих исследований по нанесению электроискровых покрытий из алюминидов на титановые сплавы ВТ20 и ВТ3-1 [14; 15]. Для улучшения характеристик электроискровых Ti-Al покрытий было предложено модифицировать электродный материал алюминид $\mathrm{Ti}_{3} \mathrm{Al}$ - посредством добавления в него тугоплавких соединений, таких как оксид алюминия, карбид вольфрама и карбид титана [16;17]. Показано, что добавки оксида алюминия и карбида титана повышают износостойкость и жаростойкость таких покрытий. В данной работе изучено влияние добавки в $\mathrm{Ti}_{3} \mathrm{Al}$ карбида бора, который является одним из перспективных материалов для упрочнения титановых сплавов [18]. Проведено исследование жаростойкости и износостойкости электроискровых покрытий из боросодержащего интерметаллидного сплава, осажденного на титановый сплав ВТ20 в среде аргона и азота. 
ПяЧИН С. А., БуРКОВ А. А., ВЛАСОВА Н. М., КИРИЧЕНКО Е. А., МОКРИЦКИЙ Б. Я., ЗАЙКОВА Е. Р.

ИЗНОСОСТОЙКОСТЬ И ЖАРОСТОЙКОСТЬ ЭЛЕКТРОИСКРОВЫХ ПОКРЫТИЙ НА ОСНОВЕ Ті

\section{Материалы и методы исследования}

Электродные материалы (аноды) были получены методом порошковой металлургии из стружки технического титана (сплав ВТ1-0) и алюминиевой пудры ПАП-1 со средним диаметром частиц около 25 мкм. Титановую стружку размалывали в атмосфере аргона до среднего размера частиц 9 мкм. Порошки Тi и Al были взяты в мольных долях 3:1, к ним был добавлен порошок карбида бора $\mathrm{B}_{4} \mathrm{C}$ в количестве 10 вес.\%. Полученную смесь перемешивали в шаровой мельнице РМ 400 в течение 4 ч в аргоне при скорости вращения 250 об/мин, после чего она была спрессована и спечена при температуре $1400{ }^{\circ} \mathrm{C}$ в течение 3 ч в вакууме с последующим охлаждением в печи. Электроды были получены в форме брусков с размерами $4 \times 4 \times 40$ мм, поэтому их можно было использовать без дополнительной обработки в качестве легирующих электродов - анодов.

Рентгеновская дифрактограмма электрода, изготовленного из $\mathrm{Ti}$ и $\mathrm{Al}$ с добавкой $\mathrm{B}_{4} \mathrm{C}$, показана на рис. 1. Установлено, что в процессе спекания формируются интерметаллиды $\mathrm{Ti}_{3} \mathrm{Al}$ и $\mathrm{Ti}_{2} \mathrm{Al}$, a также диборид титана $\mathrm{TiB}_{2}$ и карбид титана $\mathrm{TiC}$, комплексный карбид титана-алюминия $\mathrm{Ti}_{4} \mathrm{Al}_{2} \mathrm{C}_{2}$. Примечательно, что в полученном сплаве исходный карбид бора отсутствует. Данный факт объясняется протеканием твердофазной реакции $3 \mathrm{Ti}+\mathrm{B}_{4} \mathrm{C} \rightarrow 2 \mathrm{TiB}_{2}+\mathrm{TiC}$ в условиях продолжительной выдержки порошков при высокой температуре.

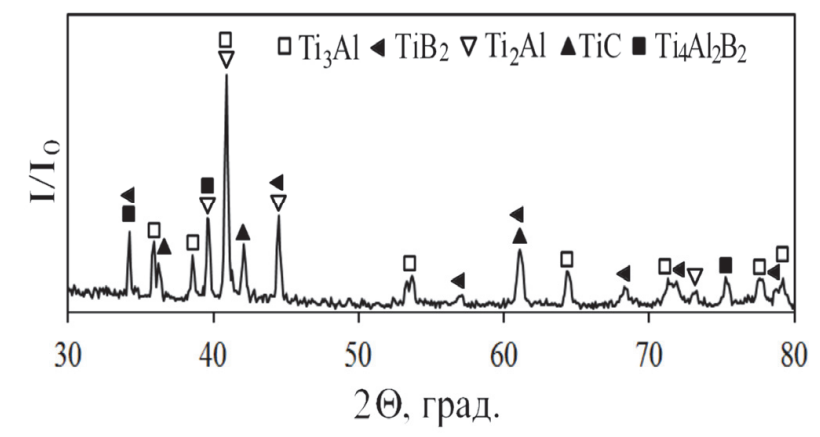

Рис. 1. Рентгеновские дифрактограммы электродного материала из $\mathrm{Ti}_{3} \mathrm{Al}$ с добавкой $\mathrm{B}_{4} \mathrm{C}$

Интерметаллидные покрытия были нанесены с помощью электроискровой установки IMES-40. Частота следования разрядных импульсов составляла 1 кГц, а длительность разрядов 100 мкс. Амплитуда импульсов тока была $110 \pm 10$ А; межэлектродное напряжение - $30 \pm 5$ В, частота колебаний вибратора - 100 Гц. Покрытия осаждали на пластины из титанового сплава ВТ20 с размерами $10 \times 10 \times 5$ мм при обдуве газом - аргоном или азотом. Количество перенесенного с анода на катод вещества контролировали посредством взвешивания электродов через каждую минуту электроискровой обработки на весах Vibra HT с точностью $10^{-4}$ г.

Фазовый состав полученных покрытий изучен с помощью рентгеновского дифрактометра ДРОН-7 в $\mathrm{Cu}-\mathrm{K} \alpha$ излучении. В целях идентификации линий рентгенограмм применялся программный пакет PDWin (HПП «Буревестник» и база данных PDF-2 Международного центра дифракционных данных (ICDD). Микроабразивная износостойкость и толщина покрытий были определены с помощью трибометра Calotester CSM instruments по схеме «вращающийся шарплоскость» с применением порошка оксида алюминия в качестве абразивного материала. Стойкость полученных образцов к высокотемпературной газовой коррозии исследована с применением дифференциального сканирующего анализатора STA 449 F3 Jupiter посредством нагрева и изотермической выдержки образцов при $900{ }^{\circ} \mathrm{C}$.

\section{Результаты и обсуждение}

Изучение кинетических закономерностей изменения масс электродов показало, что в процессе ЭИЛ масса анода уменьшалась, а масса катода увеличивалась (см. рис. 2), что является признаком электрической эрозии материала анода и переноса его на катод. При осаждении $\mathrm{Ti}_{3} \mathrm{Al}-\mathrm{B}_{4} \mathrm{C}$ 
сплава эрозия анода и привес катода в среде азота были меньше, чем в аргоне. Тем не менее средние значения толщин полученных покрытий примерно одинаковые - 25 - 27 мкм (см. табл. 1). Оптимальное время осаждения покрытия до наступления «порога хрупкого разрушения» не превышает 3 мин/см². Высокая скорость электроэрозии анодного материала 6 - 10 мг/мин обусловлена его низкой прочностью. Микроструктура электроискровых покрытий показана на рис. 3. Видно, что в покрытиях имеются поперечные трещины, а также хорошо различима граница между осажденным слоем и подложкой. Высокий градиент температур в области воздействия разрядов и сопутствующие термические напряжения растяжения являются основной причиной возникновения трещин в электроискровых покрытиях [19].

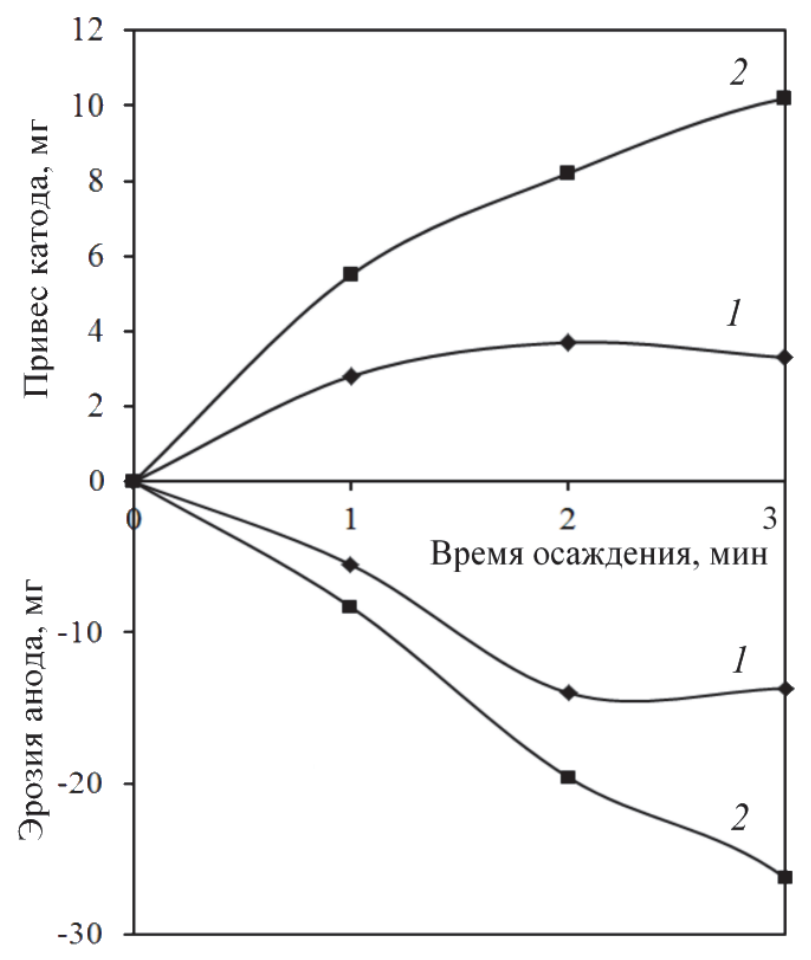

Рис. 2. Изменение масс электродов при электроискровом осаждении $\mathrm{Ti}_{3} \mathrm{Al}$ с добавкой $\mathrm{B}_{4} \mathrm{C}$ в (1) аргоне и (2) азоте

Таблица 1

Толщина и объем износа полученных электроискровых покрытий

\begin{tabular}{||c|c|c|}
\hline Среда & Толщина, мкм & Износ*, мм $^{3}$ \\
\hline Аргон & $27,1 \pm 7$ & $0,06 \pm 0,01$ \\
\hline Азот & $25,7 \pm 6$ & $0,05 \pm 0,03$ \\
\hline *Износ сплава ВТ20 $-0,14 \pm 0,02 \mathrm{~mm}^{3}$ & \\
\hline
\end{tabular}

Рентгенодифракционные исследования покрытия, нанесенного в аргоне, показали, что концентрация интерметаллида $\mathrm{Ti}_{3} \mathrm{Al}$ в нем примерно такая же, как и в легирующем электроде (см. рис. $4, a)$. Однако следует отметить, что диборид титана $\mathrm{TiB}_{2}$, присутствующий в анодном материале, при взаимодействии с титановой подложкой частично трансформируется в моноборид титана ТiB. При ЭИЛ в азоте в поверхностных слоях сплава ВТ20 в большом количестве образуется нитрид титана (см. рис. 4, б). Кроме того, наряду с алюминидом $\mathrm{Ti}_{3} \mathrm{Al}$ обнаружен интерметаллид AlTi, а вместо боридов титана присутствует борид алюминия $\mathrm{AlB}_{2}$. Вероятно, это вызвано активным вза- 
ПЯЧИН С. А., БУРКОВ А. А., ВЛАСОВА Н. М., КИРИЧЕНКО Е. А., МОКРИЦКИЙ Б. Я., ЗАЙКОВА Е. Р.

ИЗНОСОСТОЙКОСТЬ И ЖАРОСТОЙКОСТЬ ЭЛЕКТРОИСКРОВЫХ ПОКРЫТИЙ НА ОСНОВЕ Ті

имодействием титана и азота с уменьшением концентрации титана в исходном интерметаллиде и высвобождением алюминия в условиях высоких температур, развиваемых в области воздействия электрических разрядов. MAX-фаза $\mathrm{Ti}_{4} \mathrm{Al}_{2} \mathrm{C}_{2}$, обнаруженная в электроде, не содержится в покрытиях, что объясняется ее разложением под действием высоких температур в области воздействия разряда и подтверждается нашими предыдущими работами [17]. В электроде и покрытиях не был обнаружен оксид алюминия, который часто формируется при нанесении электроискровых Ti-Al покрытий в среде воздуха, что может быть объяснено флюсующим действием бора.

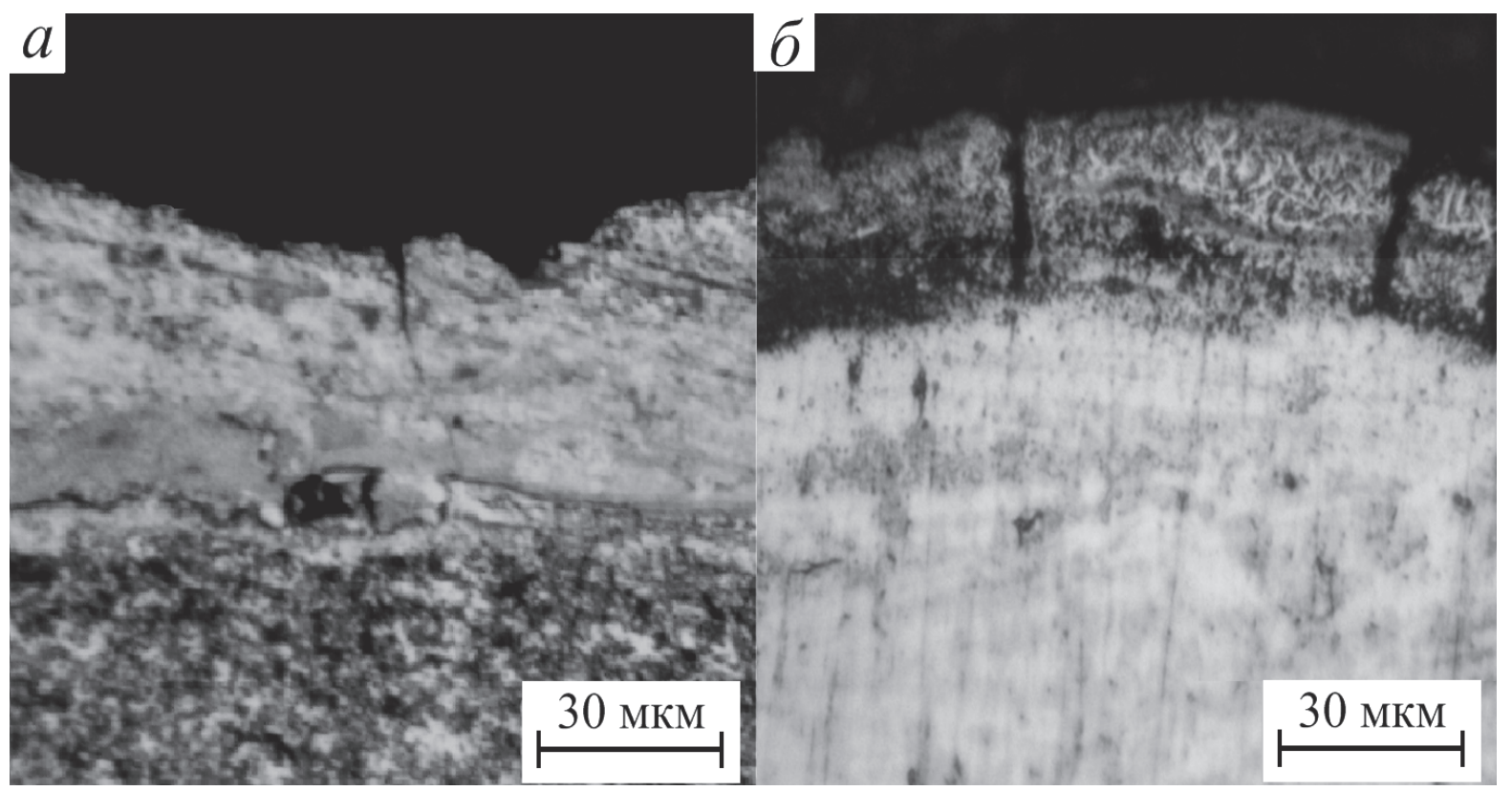

Рис. 3. Микрофотографии поперечных сечений титанового сплава ВТ20 с покрытиями, полученными в среде (а) аргона и (б) азота
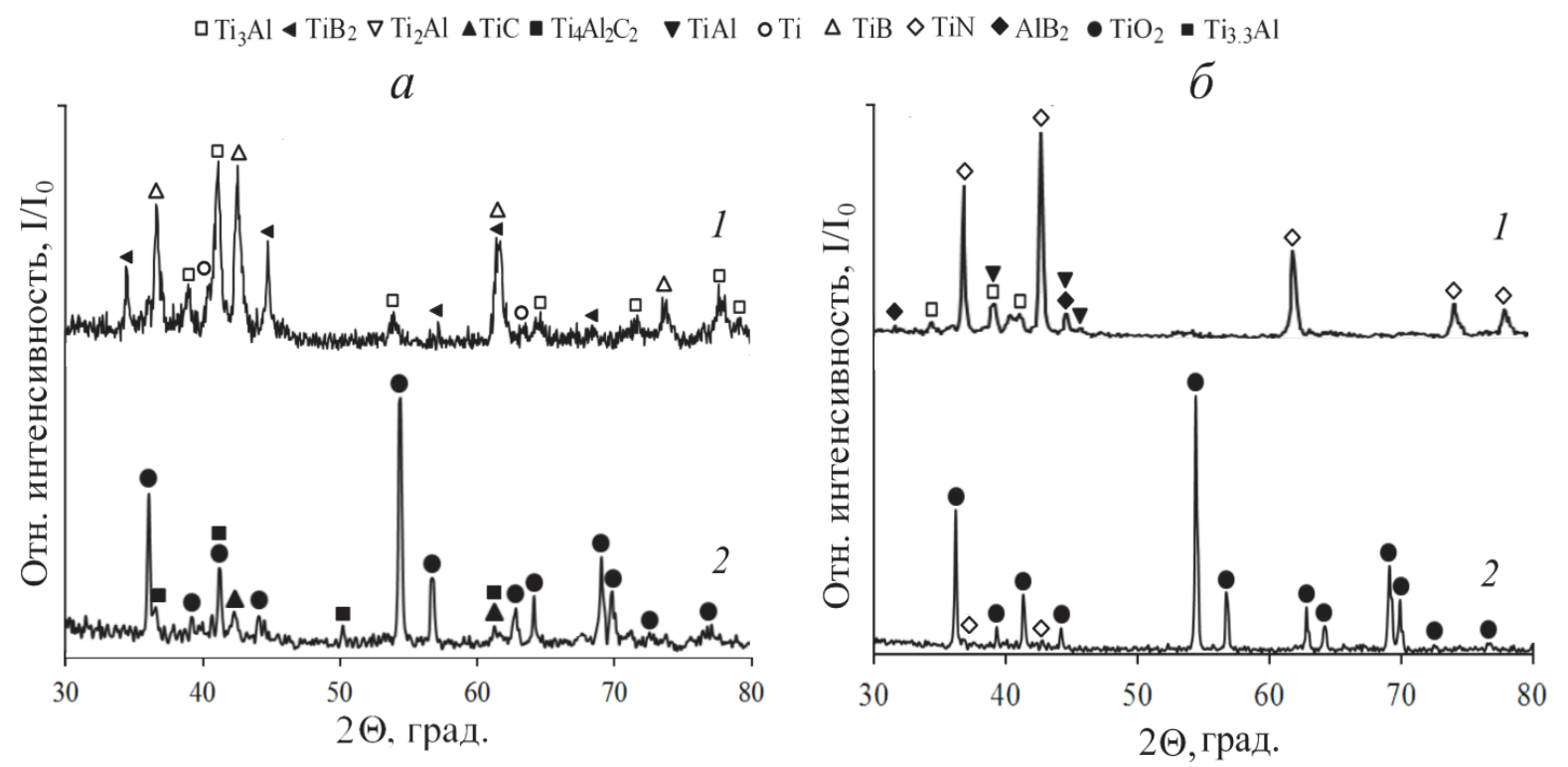

Рис. 4. Рентгеновские дифрактограммы интерметаллидных покрытий, полученных в (а) аргоне и (б) азоте, без (1) и (2) после изотермического отжига при $900{ }^{\circ} \mathrm{C}$

Результаты испытания полученных покрытий на микроабразивный износ приведены в табл. 1. Установлено, что нанесение интерметаллидных покрытий в среде аргона и азота позволяет 
снизить износ титановой подложки в 2,3 и 2,7 раза соответственно. Наибольшая стойкость электроискровых покрытий, полученных в азоте, к микроабразивному изнашиванию обусловлена высокой твердостью нитрида титана, формируемого в процессе нанесения покрытий.

При продолжительном изотермическом нагреве титанового сплава ВТ20 с электроискровыми покрытиями в воздухе при $T=900{ }^{\circ} \mathrm{C}$ наблюдается непрерывное увеличение массы испытуемых образцов (см. рис. 5), что объясняется окислением сплава, в результате которого образуется диоксид титана $\mathrm{TiO}_{2}$ в структурной модификации рутила. На рентгеновских дифрактограммах, снятых после испытания на жаростойкость, линии рутила хорошо различимы (см. рис. 4). Покрытие, полученное в аргоне, характеризуется наименьшей скоростью окисления около 6,67 мг/(мин·м²). Она более чем в 4 раза меньше, чем скорость окисления титанового сплава ВТ20.

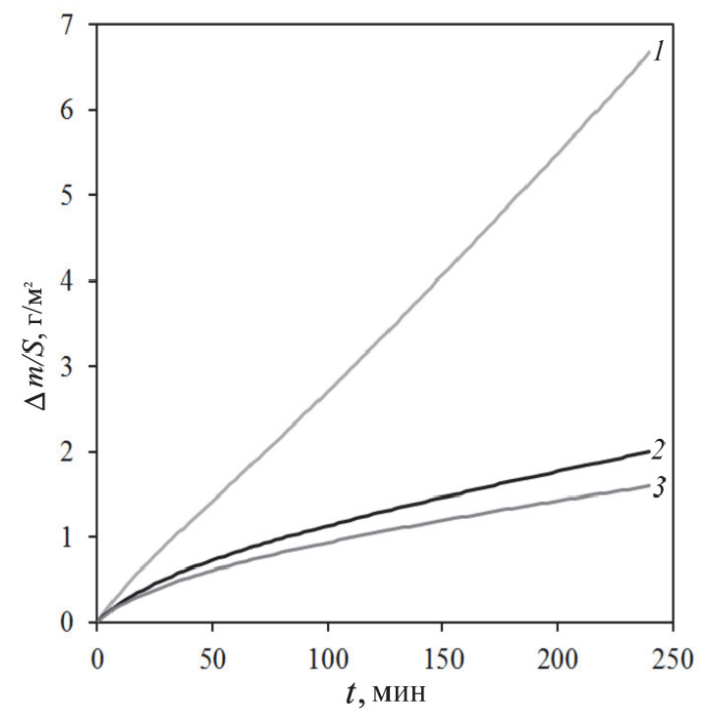

Рис. 5. Кинетика окисления образцов с покрытиями, осажденных в среде азота (2) и аргона (3) по сравнению с титановым сплавом ВТ20 (1)

\section{Выводы}

Методом порошковой металлургии получены электродные материалы на основе интерметаллида Ti3Al c 10\%-ной добавкой карбида бора. С их помощью были получены покрытия на титановом сплаве ВТ20 методом электроискрового легирования в среде аргона толщиной около 25 мкм. Анализ кинетики массопереноса показал, что наибольший привес катода достигается при электроискровом осаждении покрытий в среде аргона. В составе полученных покрытий вместо карбида бора наблюдались фазы боридов титана и алюминия. При осуществлении процесса в среде азота состав покрытий характеризовался высоким содержанием нитрида титана. Электроискровое осаждение покрытия из алюминида $\mathrm{Ti}_{3} \mathrm{Al}$ с добавкой карбида бора на титановый сплав ВТ20 позволяет повысить его устойчивость к высотемпературной газовой коррозии до четырех раз, а износостойкость поверхности титанового сплава - более чем в два раза.

\section{ЛИТЕРАТУРА}

1. Fretting Fatigue in Aircraft Components Made of Ti-Al-V Alloys / M. Sujata, M. Madan, K. Raghavendra, S. K. Bhaumik // Procedia Engineering. - 2013. - V. 55. - P. 481-486.

2. Горынин, И. В. Титан в машиностроении / И. В. Горынин, Б. Б. Чечулин. - М.: Машиностроение, 1990. $400 \mathrm{c}$.

3. Имаев, В. М. Современное состояние исследований и перспективы развития технологий интерметаллидных $\gamma$-TiAl сплавов / В. М. Имаев, Р. М. Имаев, Т. И. Оленева // Письма о материалах. - 2011. - Т. 1. - № 1. - C. 25-31. 
ПяЧИН С. А., БуРКОВ А. А., ВЛАСОВА Н. М., КИРИЧЕНКО Е. А., МОКРИЦКИЙ Б. Я., ЗАЙКОВА Е. Р.

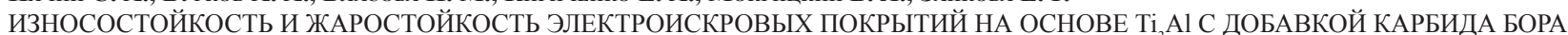

4. Формирование термически стабильной структуры в титановом сплаве с повышенным содержанием алюминия при термоводородной обработке / А. А. Ильин, С. В. Скворцова, О. Н. Гвоздева, В. А. Пожога // Титан. - 2012. - № 2 (36). - С. 4-10.

5. Семенова, И. П. Наноструктурные титановые сплавы: новые разработки и перспективы применения / И. П. Семенова, Г. И. Рааб, Р. З. Валиев // Российские нанотехнологии. - 2014. - Т. 9. - № 5-6. - С. 84-95.

6. Исследование жаростойкости и кинетики изменения элементного состава композиции из титанового сплава ВТ4-1 с жаростойкими покрытиями / Д. А. Александров, С. А. Мубояджян, А. М. Гаямов, Д. С. Горлов // Авиационные материалы и технологии. - 2014. - № 5. - С. 61-66.

7. Wu, X. Review of alloy and process development of TiAl alloys / X. Wu // Intermetallics. - 2006. - V. 14 . P. 1114.

8. PalDey, S. Cathodic arc deposited thin film coatings based on TiAl intermetallics / S. PalDey, S. C. Deevi, T. L. Alford // Intermetallics. - 2004. - V. 12. - Iss. 7-9. - P. 985-991.

9. Influence of ion implantation on nanoscale intermetallic-phase formation in $\mathrm{Ti}-\mathrm{Al}, \mathrm{Ni}-\mathrm{Al}$ and $\mathrm{Ni}-\mathrm{Ti}$ systems / I. A. Kurzina, E. V. Kozlov, Yu. P. Sharkeev, A. I. Ryabchikov, I. B. Stepanov, I. A. Bozhko, M. P. Kalashnikov, D. O. Sivin, S. V. Fortuna // Surface and Coatings Technology. - 2007. - V. 201. - P. 8463-8468.

10. Adachi, S. Improvement of adhesive strength of Ti-Al plasma sprayed coating / S. Adachi, K. Nakata // Surface and Coatings Technology. - 2007. - V. 201. - P. 5617-5620.

11. Phase composition and tribological properties of $\mathrm{Ti}-\mathrm{Al}$ coatings produced on pure $\mathrm{Ti}$ by laser cladding B. Guo, J. Zhou, S. Zhang, H. Zhou; Y. Pu; J. Chen // Applied Surface Science. - 2007. - V. 253. - P. 9301-9310.

12. Синтез поверхностных сплавов на основе $\mathrm{Ti}_{3} \mathrm{Al}$ и $\mathrm{TiAl}$ путем импульсного электронно-пучкового плавления системы $\mathrm{Al}($ пленка)/Тi(подложка) / В. П. Ротштейн, Ю. Ф. Иванов, Ю. А. Колубаева [и др.] // Письма в ЖТФ. - 2011. - Т. 37. - № 5. - С. 72-80.

13. Лазаренко, Н. И. Электроискровое легирование металлических поверхностей / Н. И. Лазаренко, Б. Р. Лазаренко // Электронная обработка материалов. - 1977. - № 3. - С. 12-16.

14. Пячин, С. А. Создание интерметаллидных покрытий электроискровым осаждением титана и алюминия на стальную подложку / С. А. Пячин, А. А. Бурков // Электронная обработка материалов. - 2015. - № 2. C. $16-23$.

15. Пячин, С. А. Формирование и исследование электроискровых покрытий на основе алюминидов титана / С. А. Пячин, А. А. Бурков, В. С. Комарова // Поверхность. Рентгеновские, синхротронные и нейтронные исследования. - 2013. - № 6. - С. 16-24.

16. Бурков, А. А. Повышение жаростойкости титанового сплава вт20 путем формирования композиционных электроискровых Ti3Al+Al/Al2O3 покрытий / А. А. Бурков // Письма о материалах. - 2015. - Т. 5. № 4 (20). - С. 371-375.

17. Влияние добавок оксидов и карбидов металлов на свойства интерметаллидных Ti3Al электроискровых покрытий / С. А. Пячин, А. А. Бурков, Н. М. Власова, Е. А. Кириченко // Фундаментальные проблемы современного материаловедения. - 2016. - Т. 13. - № 2. - С. 168-173.

18. Поверхностное упрочнение сплава ВТ6 электровзрывным легированием с карбидом бора и электроннопучковой обработкой / Т. Ю. Кобзарева, В. Е. Громов [и др.] // Обработка металлов (технология, оборудование, инструменты). - 2015. - № 4 (69). - С. 102-112.

19. Galinov, I. V. Mass transfer trends during electrospark alloying / I. V. Galinov, R. B. Luban // Surface and Coatings Technology. - 1996. - V. 79. - № 1/3. - P. 9-18. 